Provided for non-commercial research and education use. Not for reproduction, distribution or commercial use.

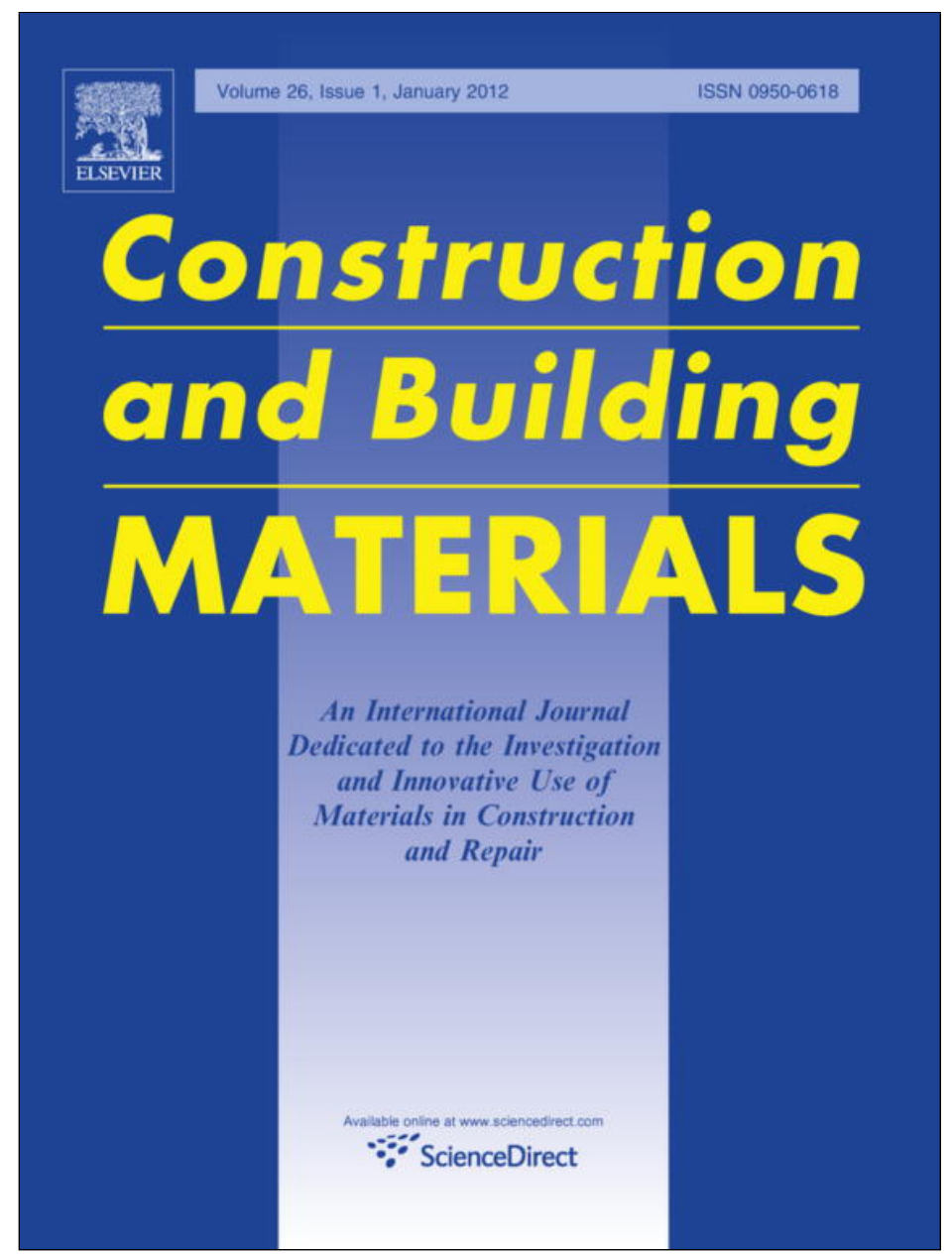

(This is a sample cover image for this issue. The actual cover is not yet available at this time.)

This article appeared in a journal published by Elsevier. The attached copy is furnished to the author for internal non-commercial research and education use, including for instruction at the authors institution and sharing with colleagues.

Other uses, including reproduction and distribution, or selling or licensing copies, or posting to personal, institutional or third party websites are prohibited.

In most cases authors are permitted to post their version of the article (e.g. in Word or Tex form) to their personal website or institutional repository. Authors requiring further information regarding Elsevier's archiving and manuscript policies are encouraged to visit:

http://www.elsevier.com/copyright 


\title{
Corn cob lightweight concrete for non-structural applications
}

\author{
Jorge Pinto ${ }^{\mathrm{a}, \mathrm{c}}$, Barbosa Vieira ${ }^{\mathrm{a}}$, Hélder Pereira ${ }^{\mathrm{a}}$, Carlos Jacinto ${ }^{\mathrm{a}}$, Paulo Vilela ${ }^{\mathrm{a}}$, Anabela Paiva ${ }^{\mathrm{a}, \mathrm{d}}$, \\ Sandra Pereira ${ }^{\mathrm{a}, \mathrm{d}}$, Vítor M.C.F. Cunha ${ }^{\mathrm{a}, \mathrm{e}}$, Humberto Varum ${ }^{\mathrm{b}, *}$ \\ ${ }^{a}$ Engineering Department, School of Science and Technology, University of Trás-os-Montes e Alto Douro, Vila Real, Portugal \\ ${ }^{\mathrm{b}}$ Civil Engineering Department, University of Aveiro, Aveiro, Portugal \\ ${ }^{\mathrm{c}}$ Associate Laboratory I3N, Aveiro, Portugal \\ ${ }^{\mathrm{d}}$ C-MADE, Centre of Materials and Building Technologies, University of Beira Interior, Covilhã, Portugal \\ e ISISE - Institute for Sustainability and Innovation in Structural Engineering, University of Minho, Portugal
}

\section{A R T I C L E I N F O}

\section{Article history:}

Received 7 November 2011

Received in revised form 8 January 2012

Accepted 25 February 2012

\section{Keywords:}

Corn cob

Lightweight concrete

Thermal insulation

Agricultural waste

Sustainability

\begin{abstract}
A B S T R A C T
A lightweight concrete using granulated corn cob (without corn) as an aggregate is proposed in this research work. Taking into account that corn cob, after extracting the corn, is generally considered an agricultural waste, an interesting economic and sustainable benefit may result by using it as a building material. Therefore, it can be an alternative sustainable lightweight aggregate solution in comparison to the most currently applied ones such as expanded clay, particles of cork, particles of expanded polystyrene (EPS), among others. The density, the compressive strength and the thermal insulation properties of a corn cob concrete were experimentally quantified. An expanded clay concrete was also studied as reference. The main results obtained are presented and discussed showing that the proposed corn cob concrete may have the adequate material properties required for a lightweight concrete for non-structural application purposes.
\end{abstract}

(c) 2012 Elsevier Ltd. All rights reserved.

\section{Introduction}

Finding new alternative affordable and sustainable products is a trend already well established among the research community worldwide. People are also much more concerned about environmental issues and demand sustainable solutions for all aspects of their daily life. Reusing, recycling and saving are terms learnt by children at an early age. The present world economic crisis also requires contention, and new affordable and sustainable products are desirable. On the other hand, the quality of these products also has to be guaranteed. Affordability, sustainability and quality are therefore the three main vectors which should dictate the design of such product. To fulfill these three requirements is the big challenge. Using organic materials and low technological processes is a good option to achieve the above requirements [1-3]. These organic materials have to be preferentially abundant and local.

In the building industry, a big range of products and building solutions based on raw organic materials have been applied. Perhaps wood, wood engineered products, cork and cork engineered products are the most traditional ones. However, different agricultural products have also been reported as possible raw organic building materials [4-9]. Some examples of these agricultural products are bagasse, cereal, straw, corn stalk, corn cob, cotton

\footnotetext{
* Corresponding author.

E-mail address: hvarum@ua.pt (H. Varum).
}

stalks, kenaf, rice husks, rice straw, sunflower hulls and stalks, banana stalks, coconut coir, bamboo, durian peel, oil palm leaves, among others. Particleboards, hardboards and fiberboards are some examples of building products that may be processed using those materials and they have mainly been studied as possible alternative thermal and acoustic insulation solutions.

Among the above identified agricultural products corn cob belongs to the set which has the additional advantage of not colliding with the worldwide food stock and of being generally considered as agricultural waste. A recent research work [9] has reported that the corn cob may have a similar microstructure and chemical elementary composition to the extruded polystyrene (XPS).

The main scope of this research work consists on analyzing the potential use of corn cob granulate (without containing any corn, i.e. an agricultural waste) as a sustainable aggregate solution of lightweight concrete and as an alternative to commonly applied products such as: expanded clay, particles of expanded polystyrene (EPS), particles of cork or other lignocelluloses wastes [10]. Since corn cob is generally considered an agricultural waste, an interesting economic and sustainable benefit may be achieved through this proposed technological solution. Within the authors' knowledge the utilization of corn cob in concrete is quite novel, and the only known use is that of corn cob ash in blended cement concretes [11-13].

The lightweight corn cob concrete, presented in this paper, was designed mainly for using on the regularization of layers of 
pavements. Some of the expected requirements of a regularization layer building solution are: lightweight, insulation capacity (thermal and/or acoustic), and durability and being economic. Therefore, the density, the compressive strength and the thermal insulation performance were the material properties assessed of the proposed corn cob concrete within this research work. In order to evaluate and compare the performance of corn cob concrete, in parallel, conventional lightweight concrete using expanded clay was developed and tested.

This paper is structured as follows, firstly, some possible lightweight concrete applications are presented and also some common lightweight aggregates are identified. Secondly, the compressive strength of corn cob and expanded clay concrete samples are assessed. The sample preparation and used equipment are described, and the experimental results obtained are presented and discussed. Thirdly, an alternative expedite experimental setup for thermal insulation performance assessment of lightweight concrete samples is proposed. The inherent facility, the sample preparation, the equipment used and the test preparation are presented and described in detail. The experimental results obtained are presented, analyzed and discussed, and the thermal transmission coefficient of the two lightweight concrete samples is quantified. Finally, the main conclusions of this research work are drawn.

\section{Context}

In order to guarantee the architectural design performance of a pavement, a regularization layer is often used (detail 3 in Fig. 1) as a technological building solution. In most of the cases, a cement mortar or a lightweight concrete are the materials used in this regularization layer. This situation may occur on the pavements located on the ground floor (Fig. 1a), intermediate floors (Fig. 1b) or on the top floor (i.e. terraces), Fig. 1c. Associated to the regularization layer another layer of a thermal or/and acoustic insulation material is also commonly applied (see detail 4 in Fig. 1). In the Portuguese context, thicknesses between $3 \mathrm{~cm}$ and $10 \mathrm{~cm}$ of the regularization layer are the most common solutions. This thickness depends on the location of the pavement, the type of the expected building floor utilization, among other factors. Lightweight, insulation capacity, durability and cost-effectiveness are some of the expected requirements for this constructive system (i.e. regularization and insulation layers).

Alternative solutions to the above mentioned constructive systems have been proposed and successfully applied. Some of those solutions use lightweight aggregates such as expanded clay, particles of cork or particles of expanded polystyrene (EPS). This research work intends to propose another alternative solution to the system described above and focus on analyzing the potential of using particles of corn cob, Fig. 2a and b, as lightweight aggregate for concrete. An expanded clay (Fig. 2c) concrete is adopted as reference. The analyzed material properties are the density, the compressive strength and the thermal insulation capacity.

\section{Mechanical behavior assessment}

At this stage, the compression strength was the mechanical property analyzed because it is the most required for this context. Meanwhile, good compressive strength is also an indicator of good impact and abrasion capacities.

\subsection{Sample preparation and test equipment}

The compressive strength of both corn cob and expanded clay concrete was assessed with cubic specimens of $15 \mathrm{~cm}$ edge length. In both cases, a weight ratio of 6:1:1 (i.e. lightweight

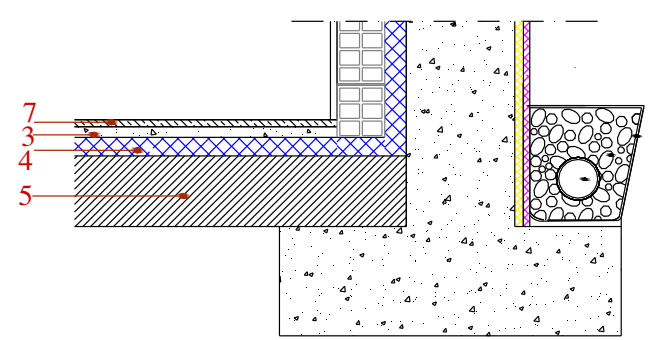

(a) Ground floor

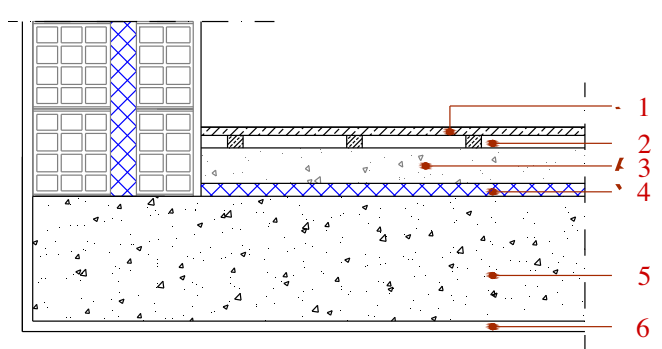

(b) Upper floor

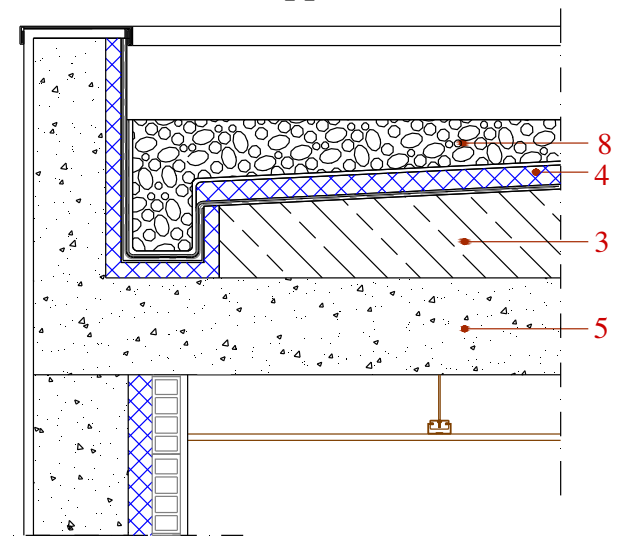

(c) Terrace

Fig. 1. Examples of applications of regularization layer. Key: 1 - Wood floor; 2 - Air layer; 3 - Regularization layer; 4 - Extruded polystyrene (XPS); 5 - Pavement; 6 - Plaster; 7 - Ceramic tiles; 8 - Pebble.

aggregate:Portland cement:water) was adopted. This is a currently applied ratio for the regularization layer of expanded clay concrete applications in the Portuguese context. Fig. 3 exemplifies some steps of the corn cob concrete sample processing such as adding the components (Fig. 3a), curing process (Fig. 3b) and the unmolding step (Fig. 3c). Fig. $3 \mathrm{~b}$ also indicates the corn cob concrete sample type used in the compression test (I, Fig. 3b) and the corn cob concrete sample type used in the thermal insulation performance test (II, Fig. 3b) related to Section 4 . On the other hand, Fig. 4 features the same steps of the expanded clay concrete sample processing. In both cases, the curing occurred under controlled thermal and hygrometric conditions.

At the age of 28 days, the samples were tested in terms of compression. Previously, they had been measured and their mass had been assessed by using a digital weighing-machine HP-20K. An ALPHA 3-3000D compression testing rig with an ultimate carrying capacity of $3000 \mathrm{kN}$ was used, as depicted in Fig. 5.

\subsection{Experimental results and discussion}

The mass, density, ultimate compression load and the compressive strength were the material properties evaluated during the compressive test. The values of these properties are presented in 


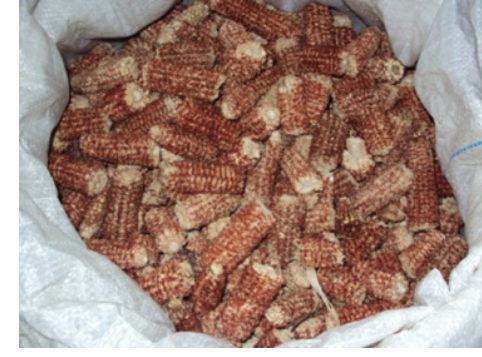

(a) Corn cob (without corn)

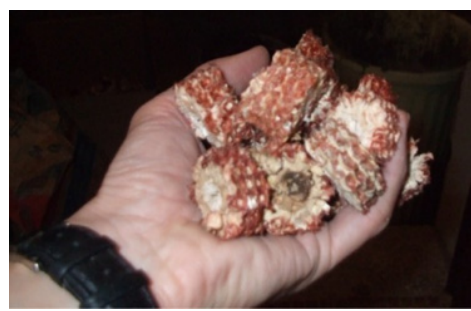

(b) Granulate of corn cob

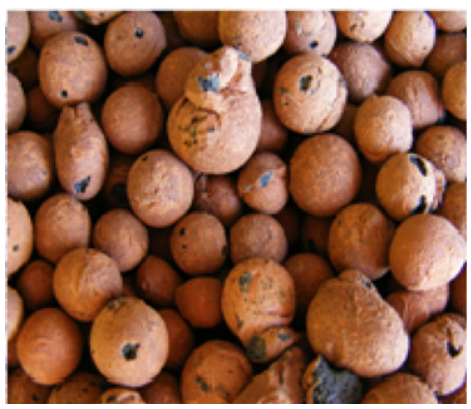

(c) Expanded clay

Fig. 2. Expanded clay $v s$ corn cob (without corn).

Tables 1 and 2 for the corn cob and the expanded clay concrete specimens, respectively.

The average evaluated density of the corn cob concrete samples (ratio $6: 1: 1$ ) was $382.2 \mathrm{~kg} / \mathrm{m}^{3}$ which is lower than the respective material property of the expanded clay concrete samples (ratio 6:1:1), $576.3 \mathrm{~kg} / \mathrm{m}^{3}$, see Tables 1 and 2. Since a low specific weight is probably one of the most important qualities for a regularization layer, i.e. without any special needs in terms of mechanical resistance (for a non-structural application), this experimental result corroborates the potential use of this agricultural waste product as a natural lightweight aggregate within concretes for regularization layers. The compressive strength of the expanded clay concrete (average value of $1360 \mathrm{kN} / \mathrm{m}^{2}$, Table 2) is clearly higher than the correspondent property of the corn cob concrete (average value of $120 \mathrm{kN} / \mathrm{m}^{2}$, Table 1 ). The fact that the corn cob concrete samples were not yet completely dried at the age of 28 days, and that the granulometry of the corn cob particles may require improvements in terms of range of dimensions and weight proportions; and the adopted corn cob concrete components ratio may be inadequate, may justify the above discrepancy. At the same time, it is important to underline that the obtained expressive compressive strengths difference relies on the fact that the authors are analyzing two different materials. In order to figure out the impact of the corn cob concrete component ratio, four additional samples were casted (ratio 3:1:1) and tested under compression at the age of 28 days. The respective experimental results obtained are presented in Table 3 . The compressive strength increased nearly $220 \%$ (from $120 \mathrm{kN} / \mathrm{m}^{2}$, Table 1 ; to $392.2 \mathrm{kN} / \mathrm{m}^{2}$, Table 3 ) associated to the fact that the amount of corn cob particles in relation to the binder content had been reduced (from 6:1:1, Table 1 and to $3: 1: 1$, Table 3 ). However, the improvement on the compressive strength is still insufficient to reach the strength obtained with the expanded clay concrete $\left(392.2 \mathrm{kN} / \mathrm{m}^{2}\right.$, Table 3; against $1360 \mathrm{kN} /$ $\mathrm{m}^{2}$, Table 2). At the same time, it was verified that there was a significant increment of the density (from $382.2 \mathrm{~kg} / \mathrm{m}^{3}$, Table 1 and to $777.8 \mathrm{~kg} / \mathrm{m}^{3}$, Table 3). It is worth underlining that the corn cob concrete samples processed with the ratio of 3:1:1 were also not completely dried at the age of 28 days.

Furthermore, an interesting resilience capacity of the corn cob concrete was noticed while carrying out the compression test. An irrelevant shrinkage potential is expected with the proposed corn cob concrete mixture.

\section{Thermal performance assessment}

Usually, in order to evaluate the thermal properties (e.g. the thermal transmission coefficient, $U$, or the thermal conductivity, $\lambda$ ) of materials or building component systems, a testing thermal cell is currently applied. However, in this research work, an alternative experimental procedure based in [14] was applied. In this case, the facilities, the sample preparation, the equipment and the test procedures are crucial [15]. Therefore, in the context of this paper, these aspects will be explained in detail in the following sections.

\subsection{Facility and sample preparation}

A confined room with $4.00 \mathrm{~m} \times 3.00 \mathrm{~m} \times 2.54 \mathrm{~m}$ (length $\times$ width $\times$ height) was used as an alternative expedite solution of a testing thermal cell, Fig. 6a. This room must have windows preferentially oriented to north in order to avoid the direct sunshine incidence on the samples. In this case, there are five windows in the northeast façade of the confined room, Fig. $6 a$.

Corn cob and expanded clay concrete samples were specifically produced for this test. These samples were sized $40 \mathrm{~cm} \times 20 \mathrm{~cm} \times$ $5 \mathrm{~cm}$ (width $\times$ height $\times$ thickness) as illustrated in Fig. 3b (detail II) for the corn cob concrete samples. Meanwhile, the XPS panel was

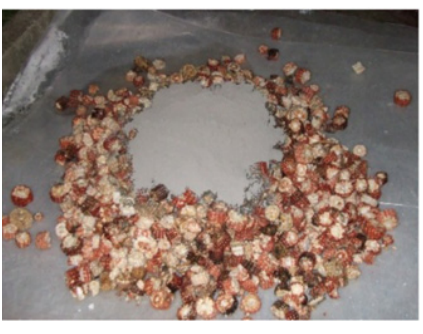

(a) Adding

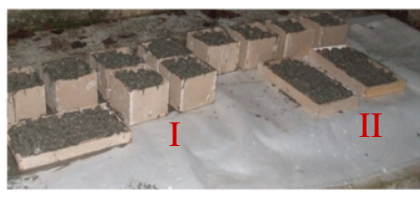

(b) Curing

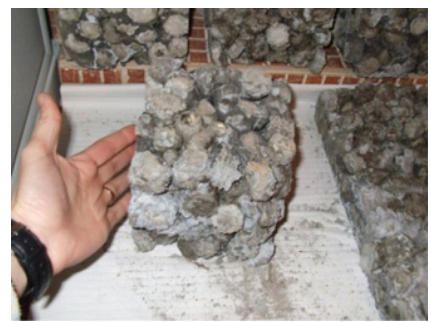

(c) Unmoulding

Fig. 3. Processing of the corn cob concrete samples for the compression test. 


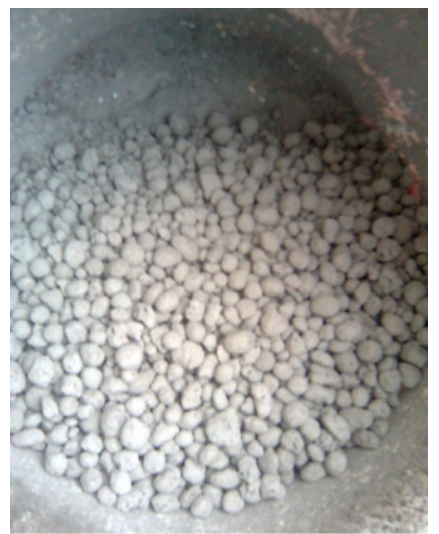

(a) Adding

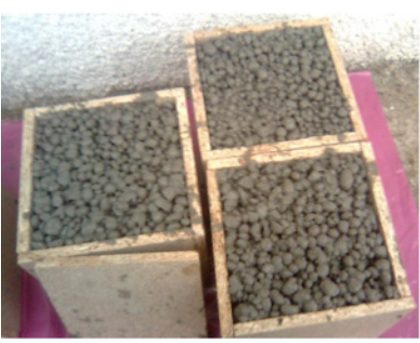

(b) Curing

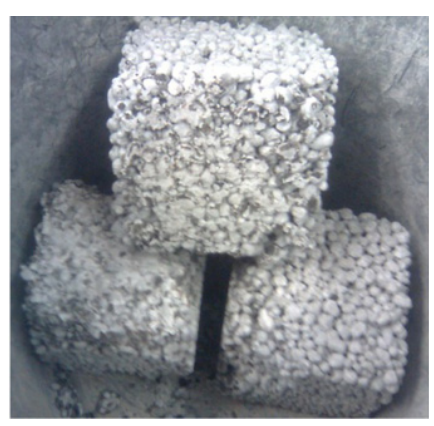

(c) Unmoulding

Fig. 4. Processing of the expanded clay concrete samples for the compression test.

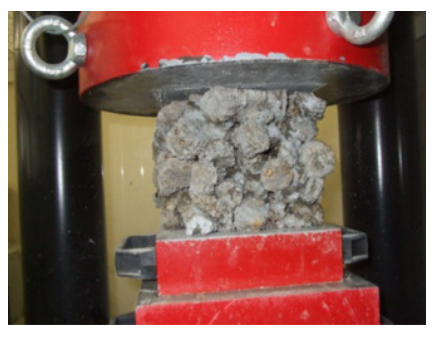

(b) Corn cob concrete sample

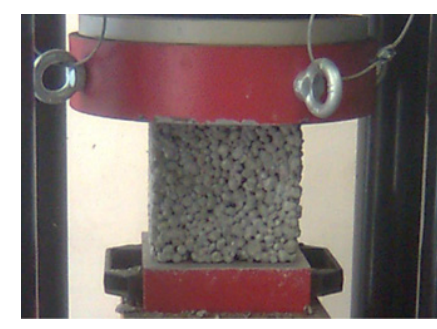

(c) Expanded clay concrete sample

Fig. 5. Compression test procedure.

Table 1

Compression test results of the corn cob concrete samples (ratio 6:1:1).

\begin{tabular}{llllr}
\hline Sample & Mass $(\mathrm{kg})$ & Density $\left(\mathrm{kg} / \mathrm{m}^{3}\right)$ & Ultimate load $(\mathrm{kN})$ & \multicolumn{2}{c}{ Compression strength $\left(\mathrm{kN} / \mathrm{m}^{2}\right)$} \\
\hline 1 & 1.21 & 358.5 & 2.0 & 8.1 \\
2 & 1.46 & 432.6 & 1.9 & 26.9 \\
3 & 1.22 & 361.5 & 1.8 & 84.4 \\
4 & 1.27 & 376.3 & 2.7 & 80.0 \\
Average & 1.29 & 382.2 & 120.0 \\
\hline
\end{tabular}

Table 2

Compression test results of the expanded clay concrete samples (ratio 6:1:1).

\begin{tabular}{|c|c|c|c|c|}
\hline Sample & Mass (kg) & Density $\left(\mathrm{kg} / \mathrm{m}^{3}\right)$ & Ultimate load (kN) & Compression strength $\left(\mathrm{kN} / \mathrm{m}^{2}\right)$ \\
\hline 1 & 2.04 & 604.4 & 38.7 & 1720.0 \\
\hline 2 & 1.87 & 554.1 & 24.5 & 1088.9 \\
\hline 3 & 1.86 & 551.1 & 24.0 & 1066.7 \\
\hline 4 & 2.01 & 595.6 & 35.2 & 1564.4 \\
\hline Average & 1.95 & 576.3 & 30.6 & 1360.0 \\
\hline
\end{tabular}

Table 3

Compression test results of the corn cob concrete samples (ratio 3:1:1).

\begin{tabular}{lllll}
\hline Sample & Mass $(\mathrm{kg})$ & Density $\left(\mathrm{kg} / \mathrm{m}^{3}\right)$ & Ultimate load $(\mathrm{kN})$ & \multicolumn{1}{c}{ Compression strength $\left(\mathrm{kN} / \mathrm{m}^{2}\right)$} \\
\hline 1 & 2.3 & 681.5 & 11.5 & 280.0 \\
2 & 3.2 & 948.1 & 8.6 & 311.1 \\
3 & 2.5 & 740.7 & 8.9 & 382.2 \\
4 & 2.5 & 740.7 & 8.8 & 395.6 \\
Average & 2.6 & 777.8 & 392.2 \\
\hline
\end{tabular}

$76 \mathrm{~cm} \times 64 \mathrm{~cm} \times 5 \mathrm{~cm} \quad$ (width $\times$ height $\times$ thickness) (detail a, Fig. 6b). The size of the XPS support panel (i.e. width and height) is similar to the size of the existing windows of the confined room.
In this case, the windows identified as I and II in Fig. 6 were used. A hole was done in the central part of the XPS panel with the same shape and dimensions of the samples. The corn cob (detail b, 


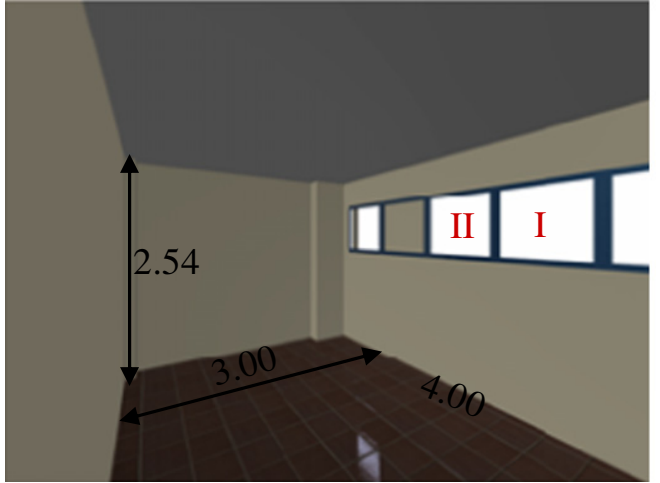

(a) Confined room (m)

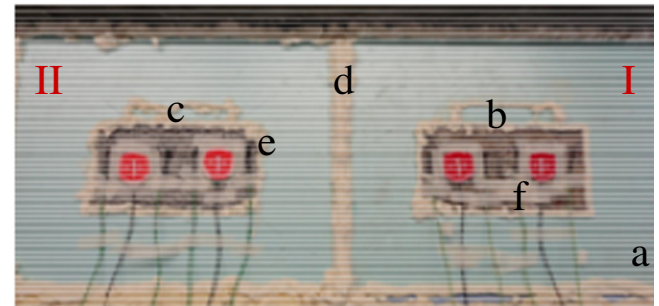

(b) Set up

Fig. 6. Testing facility and sample testing setup. Key: a - XPS; b - Corn cob concrete sample; c - Expanded clay concrete sample; d - Polyurethane foam; e - Superficial temperature sensor; f - Heat flux sensor.

Fig. 6b) and the expanded clay (detail c, Fig. 6b) concrete samples were then placed in the hole of the XPS panel and both materials were connected by polyurethane foam. The set (i.e. sample and XPS) replaced a window and was also fixed by polyurethane foam, (detail d, Fig. 6b). All these experimental procedures require additional care in order to avoid any undesirable insulation voids, thermal bridges, non-insulated headers and other faults which may compromise the feasibility of the final results.

\subsection{Equipment and test preparation}

In this research work two heat flux meter transfer systems (i.e. one for each sample), two thermo hygrometric devices and a domestic heater device were adopted as the main equipment. Each heat flux meter transfer system included two heat flux sensors (detail f, Fig. 6b), four superficial temperature sensors (detail e, Fig. 6b), a data logger and a computer. The heat flux sensors make it possible to measure the heat flow across a sample. A heat flow occurs when there is a significant thermal gradient between the two surfaces of a sample (i.e. indoor and outdoor surfaces). In this case, this gradient results from the existing thermal gradient between indoor and outdoor temperatures. The superficial temperature sensors were used as a complement and as reference of the heat flux measurement sensors, and in order to evaluate the inner surface temperature of the samples. Two superficial temperature sensors by heat flux sensor were adopted as Fig. 6b shows. One thermo hygrometric device was placed indoors and another one was placed outdoors. The heat transfer and the superficial temperature sensors were fixed on the inner face of the samples by adhesive tape, Fig. 6b. This procedure is extremely important taking into account the rugosity of the surface of the two tested samples types, which were corn cob concrete samples (ratio 6:1:1, aged 60 days) and expanded clay concrete samples (ratio 6:1:1, aged 60 days). It is imperious to guarantee a perfect contact between the surfaces of the heat flux sensor and the inner face of the samples, and to avoid any possibility of the sensors coming off during the test performance. According to [14], the test duration is related to the thermal inertia of the building component under study. For a high thermal inertia building component a minimum of fourteen days test duration is recommended. On the other hand, for a low thermal inertia building component a minimum of 3 days of test duration is recommended. In this case, five days test duration was considered assuming that both types of lightweight concrete samples under study had low thermal inertia.

In the Portuguese context and, in particular, in the northeastern region of this country, it is convenient to perform this test during the winter or the summer because it is easy to ensure the desirable uniform high thermal gradient between indoor and outdoor spaces. A uniform high thermal gradient between indoors and outdoors is desirable because it corresponds to the ideal condition to allow a significant heat flow across the sample. During the winter, this condition can be achieved by using a simple domestic heater device placed indoors and able to keep the room constantly warm. In contrast, during the summer, an air conditioner can be used to keep the room constantly cool. In this case, the test was performed during the winter, namely, in February of 2011. Therefore, a uniform high thermal gradient between indoors and outdoors was achieved by placing a common domestic heater device in the confined test room.

\subsection{Experimental results and discussion}

The two types of lightweight concrete samples were tested in parallel. A continuous data acquisition was carried out during the test (in-between $10 \mathrm{~min}$ intervals $(n)$ ). That acquired data comprised the values of the heat flow across the corn cob concrete sample $\left(q^{\prime} 1(n)\right.$ and $q^{\prime} 2(n)$, measured by the two used heat flux sensors placed on this sample) and the values of the heat flow across the expanded clay concrete sample $(q 1(n)$ and $q 2(n)$, measured by the two used heat flux sensors placed on this sample). It also included the interior and the exterior temperatures $(\operatorname{Ti}(n)$ and $T e(n)$ ), and the relative humidity. Fig. 7 depicts graphically the above mentioned registered data.

In this case, almost $48 \mathrm{~h}$ were necessary ( $\Delta T$ stabilizing, Fig. 7 ) to stabilize the interior temperature at $20^{\circ} \mathrm{C}$ of the confined room. Meanwhile, the exterior temperature had shown its natural and expected swing in a day time (e.g. $\Delta$ Tnight and $\Delta$ Tday, Fig. 7). For that period of the year, in the north region of Portugal, the exterior temperature was always lower than the interior temperature. Therefore, adequate thermal gradients were guaranteed (e.g. details I and II, Fig. 7).

According to [14], the thermal transmission coefficient $(U)$ can be quantified by:

$$
U(\text { ntotal })=\frac{\sum_{n=1}^{n \text { total }} q(n)}{\sum_{n=1}^{\text {ntotal }}(\operatorname{Ti}(n)-T e(n))}
$$

where $U$ is the thermal transmission coefficient, $q(n)$ is the heat flow across the sample at the moment $n, \operatorname{Ti}(n)$ and $\operatorname{Te}(n)$ are the interior and the exterior temperature at the moment $n$, respectively; ntotal is the total number of moments in which the data were registered.

Taking into account that two heat flux sensors were used by each sample, corresponding to $q 1(n)$ and $q 2(n)$, it was possible to estimate two thermal transmission coefficients for each sample, 


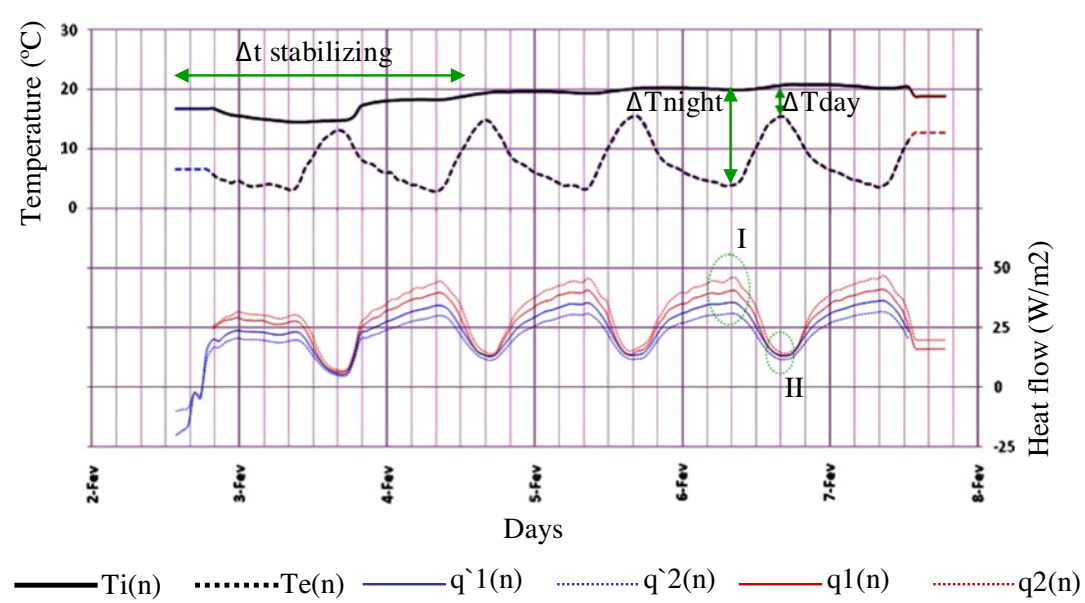

Fig. 7. Interior $(\operatorname{Ti}(n))$ and exterior $(\operatorname{Te}(n))$ temperatures. Heat flow across the corn cob $\left(q^{\prime} 1(n)\right.$ and $\left.q^{\prime} 2(n)\right)$ and the expanded clay $(q 1(n)$ and $q 2(n))$ concrete samples.

Table 4

Thermal transmission coefficient $\left(U^{\prime}(\right.$ ntotal $\left.)\right)$ of the two lightweight concretes.

\begin{tabular}{ll}
\hline Sample & $U^{\prime}($ ntotal $)\left(\mathrm{W} / \mathrm{m}^{2}{ }^{\circ} \mathrm{C}\right)$ \\
\hline Corn cob concrete & 1.99 \\
Expanded clay concrete & 2.72 \\
\hline
\end{tabular}

U1(ntotal) and U2(ntotal), by applying Eq. (1). Thus, the thermal transmission coefficient of each sample $\left(U^{\prime}(\right.$ ntotal)) can be the average value of U1(ntotal) and U2(ntotal) and according to the following equation:

$U^{\prime}($ ntotal $)=\frac{U 1(\text { ntotal })+U 2(\text { ntotal })}{2}$

where $U^{\prime}($ ntotal) is the thermal transmission coefficient of the sample, $U 1$ (ntotal) and $U 2$ (ntotal) is the thermal transmission coefficient related to the data registered by the heat flux sensors 1 and 2 , respectively.

Based on the prior experimental data (Fig. 7) and applying the previous expressions the thermal transmission coefficient of each lightweight concrete sample can be estimated. These coefficients are presented in Table 4.

The results of Table 4 show the thermal insulation performance benefits of using corn cob particles as an aggregate of lightweight concrete when compared to a lightweight concrete with expanded clay.

\section{Conclusions}

Granulate of corn cob, without containing any corn, is proposed as an alternative organic aggregate of lightweight concrete. Generally, corn cob is considered an agricultural waste. Using it as an alternative to expanded clay, cork, EPS, among other possibilities may have an interesting economic and sustainable benefit. At this stage, the obtained experimental results indicate that corn cob concrete processed according to a ratio of $6: 1: 1$ (corn cob granulate:Portland cement:water) may have acceptable material properties. For instance, the density and the thermal performance properties are in accordance with the respective material properties of an expanded clay concrete. However, the studied corn cob concrete has shown low compression strength when compared to the expanded clay concrete. Aspects related to the granulometry of the corn cob particles, the ratio of components and the curing time may justify the above vulnerability. Nevertheless it may be suitable for non-structural application purposes, such as pavement regularization layers. Further research will be carried out to solve the above mentioned low concrete strength.

\section{References}

[1] Perez-Garcia John, Lippke Bruce, Briggs David, Wilson James B, Bowyer James, Meil Jaime. The environmental performance of renewable building materials in the context of residential construction. J Wood Fiber Sci 2005;37:3-17.

[2] Korjenic Azra, Petránek Vít, Zach Jiř́i, Hroudová Jitka. Development and performance evaluation of natural thermal-insulation materials composed of renewable resources. Energy Build 2011;43:2518-23.

[3] Ortiz Oscar, Castells Frances, Sonnemann Guido. Sustainability in the construction industry: a review of recent developments based on LCA. Constr Build Mater 2009;23:28-39.

[4] Younquist J, English B, Spelter H, Chow P. Agricultural fibers in composition panels. In: Proceedings of the 27th international particleboard/composite materials symposium, 1993 March 30-31, Pullman, WA. Pullman, WA: Washington State University, 1993. p. 133-52.

[5] Chow P. Dry formed composite board from selected agricultural residues. World consultation on wood based panels. New Delhi, India: Food and Agriculture Organization of the United Nations; 1974.

[6] Lertsutthiwong P, Khunthon S, Siralertmukul K, Noomun K, Chandrkrachang S. New insulating particleboards prepared from mixture of solid wastes from tissue paper manufacturing and corn peel. Bioresour Technol 2008;99:4841-5.

[7] Khedari J, Nankongnab N, Fotios S. Agricultural waste materials as thermal insulation for dwellings in Thailand: preliminary results. In: PLEA 2008: 25th conference on passive and low energy architecture, Dublin, 22nd-24th October 2008; 2008.

[8] Stone N. Thermal performance of straw bale wall systems. Ecol Build Net (EBNet) 2003:1-7.

[9] Pinto J, Paiva A, Varum H, Costa A, Cruz D, Pereira S, et al. Corn's cob as a potential ecological thermal insulation material. Energy Build 2011:43:1985-90.

[10] Karade SR. Cement-bonded composites from lignocellulosic wastes. Constr Build Mater 2009;23:28-39.

[11] Adesanya DA, Raheem AA. Development of corn cob ash blended cement. Constr Build Mater 2009;23:347-52.

[12] Adesanya DA, Raheem AA. A study of the workability and compressive strength characteristics of corn cob ash blended cement concrete. Constr Build Mater 2009;23:311-7.

[13] Adesanya DA, Raheem AA. A study of the permeability and acid attack of corn cob ash blended cements. Constr Build Mater 2010;24:403-9.

[14] ISO 9869. Thermal insulation - building elements - in situ measurement of thermal resistance and thermal transmittance. International Organization for Standardization (ISO); 1994.

[15] Paiva A, Pereira S, Sá A, Cruz D, Varum H, Pinto J. A contribution to the thermal insulation performance characterization of corn cob particleboards. Energy Build 2012;45:274-9. 